\title{
Characterization of bacterial communities in wetland mesocosms receiving pharmaceutical-enriched wastewater
}

\author{
Dongqing Zhang ${ }^{\mathrm{a}, *, 1}$, Jinxue Luo ${ }^{\mathrm{b}, 1}$, Zarraz May Ping Lee ${ }^{\mathrm{a}}$, Yogananda Maspolim ${ }^{\mathrm{a}}$, \\ Richard M. Gersberg ${ }^{\mathrm{c}}$, Yu Liu ${ }^{\mathrm{a}, \mathrm{d}}$, Soon Keat Tan ${ }^{\mathrm{a}, \mathrm{d}}$, Wun Jern Ng ${ }^{\mathrm{a}, \mathrm{d}}$ \\ a Advanced Environmental Biotechnology Centre, Nanyang Environment E' Water Research Institute, Nanyang Technological University, 1 Cleantech Loop, \\ \#06-10, Singapore 637141, Singapore \\ ${ }^{\mathrm{b}}$ Key Laboratory of Environmental Biotechnology, Research Center for Eco-Environmental Sciences, Chinese Academy of Sciences, Beijing 100085, PR China \\ c Graduate School of Public Health, San Diego State University, Hardy Tower 119, 5500 Campanile, San Diego, CA 92182-4162, USA \\ ${ }^{\mathrm{d}}$ School of Civil and Environmental Engineering, Nanyang Technological University, N1-01a-29, 50 Nanyang Avenue, Singapore 639798, Singapore
}

\section{A R T I C L E I N F O}

\section{Article history:}

Received 4 May 2015

Received in revised form

21 December 2015

Accepted 22 December 2015

Available online 13 February 2016

\section{Keywords:}

Constructed wetland

Ibuprofen

Bacterial community

Pyrosequencing

\begin{abstract}
A B S T R A C T
A 16S rRNA gene multiplex 454 pyrosequencing approach was used to characterize the structure of the bacterial community in subsurface flow constructed wetlands planted with Typha angustifolia and unplanted wetland mesocosms receiving ibuprofen-enriched wastewater at a concentration of $250 \mu \mathrm{g} \mathrm{L}^{-1}$. The removal efficiency of ibuprofen (IBP) in the planted beds (78.5\%) was significantly higher than that in the unplanted beds $(57.9 \%)(P \leq 0.05)$. The presence of ibuprofen significantly $(P \leq 0.05)$ reduced the diversity of the bacterial community. In total, 20 phyla comprising 265 genera were identified. The most predominant phyla were Firmicutes (27.6\%), Actinobacteria (26.0\%) and Proteobacteria (24.9\%), making up 57-95\% of the $16 \mathrm{~S}$ rDNA sequences. Other dominating phyla in wetland soils were Chloroflexi (7.3\%), Bacteroidetes (2.7\%), Synergistetes (2.1\%), and Acidobacteria (2.0\%). A distinct profile of bacterial community in the wetland mesocosms was observed after IBP enrichment. IBP-enrichment enhanced the relative abundance of Actinobacteria, Bacilli and $\gamma$-Proteobacteria at class level. The efficient ibuprofen removal observed in this study suggested that the IBP-enriched wetland systems may have selected a restricted group of bacteria that was able to survive best in the disturbed condition and participate in the IBP biodegradation. Our findings also indicated that the presence of macrophytes may have a vital impact on the microbial community and planted wetlands may be more robust and buffered against significant shifts in microbial composition in response to IBP-disturbance.
\end{abstract}

(ㄷ) 2016 Elsevier B.V. All rights reserved.

\section{Introduction}

Pharmaceutically active compounds (PhACs) have been regarded as emerging contaminants and provoked increasing global concern because of their continuous introduction into the aquatic environment (Daughton and Ternes, 1999; Ternes et al., 2007). Centralized wastewater treatment plants (WWTPs) have been frequently pointed out as major point sources for PhAC discharge (Carballa et al., 2004; Ellis, 2006). Since conventional WWTPs have not been specifically designed to remove PhACs, the elimination of PhACs in WWTPs is often incomplete (Joss et al.,

\footnotetext{
* Corresponding author.

E-mail address: dqzhang@ntu.edu.sg (D. Zhang).

1 These authors contributed equally to this work
}

2006). As a consequence, significant amounts of pharmaceutical residues are suspected to enter rivers, streams and surface waters through the effluents of WWTPs (Carballa et al., 2004). Despite their low concentrations (ranging from parts per billion to parts per trillion), these compounds may still exert chronic adverse effects on aquatic organisms in receiving waters and possibly pose a human health risk if the reclaimed water is returned to the water supply (Fent et al., 2006; Ternes et al., 2007).

In this regard, alternative approaches, especially eco-friendly strategies for the elimination of micropollutants are matters of great interest. Recently, a number of studies have shown that constructed wetlands (CWs) have great potential for the removal of PhACs (Hijosa-Valsero et al., 2010; Zhang et al., 2012b). In wetland systems, the intrinsic physical, chemical and biological processes may occur simultaneously for water quality improvement, including volatilization, sorption and sedimentation, phytodegradation, 
and plant uptake (Zhang et al., 2014). In particular, the complex microbial communities, which are created by the interactions between water, soil, plant and microorganisms, play a key role in wetland biogeochemical cycles and are mainly responsible for contaminant degradation in CW system (Ibekwe et al., 2007; Ligi et al., 2014). Therefore, an understanding of the diversity and structure of microbial community is important for proper functioning of a wetland system, and characterizing the shifts in the structure of microbial community may shed light on prediction of the microbial populations responsible for the degradation of the target organic pollutants (Johnsen et al., 2002). However, to date, only a limited number of studies have focused on microbial community investigations in CWs (Tietz et al., 2007; Truu et al., 2009). And the microbial diversity of treatment wetlands has remained relatively uncharacterized, and the interactions between soil and microorganisms in wetlands are also poorly understood (Stottmeister et al., 2003). In addition, significantly missing from the literature is the influence of PhACs on microbial structure and the response of the microbial community to the presence of PhACs in wetland systems.

The application of culture-independent approaches based on the analysis of $16 \mathrm{~S}$ ribosomal RNA (rRNA) genes including fluorescence in situ hybridization (FISH), denaturing gradient gel electrophoresis (DGGE), terminal restriction fragment length polymorphism (T-RFLP), and clone library have led to new insights into microbial processes in CWs and can provide direct evidence for the presence of specific microorganisms influencing pollutant removal (Ibekwe et al., 2007; Truu et al., 2009). More recently, next generation 454 pyrosequencing approach, which is operated as a high-throughput sequencing tool with longer read length, has become an effective method to fully explore the microbial diversity in the environment (Roesch et al., 2007; Roh et al., 2010). In particular, this technology can provide a better understanding of the low-abundance microorganisms that are usually overshadowed by dominant populations in the environment (Roh et al., 2010). To date this approach has been used to study microbial communities in activated sludge in WWTPs (Zhang et al., 2012c), fresh water sediment (Wang et al., 2012), and submerged membrane bioreactors (Ma et al., 2013). To the best of our knowledge, there are no studies using high-throughput pyrosequencing technology to investigate the microbial communities in treatment wetlands in response to pharmaceutical-enriched wastewater.

Ibuprofen (IBP), a non-steroidal anti-inflammatory drug, was selected for this study because of its widespread usage and ubiquitous occurrence in WWTPs. Verlicchi and Zambello (2014) reviewed 118 pharmaceuticals which have been frequently detected in raw urban wastewater and indicated that ibuprofen was considered as the most commonly investigated anti-inflammatory drug with the highest influent concentration of $373 \mu \mathrm{g} \mathrm{L}^{-1}$ in raw urban wastewater. Although various removal mechanisms (e.g. sorption, sedimentation and plant uptake) may contribute to the total elimination of PhACs in CWs (Zhang et al., 2014), for polar acidic PhACs like IBP, microbial degradation is believed to be the most significant removal mechanism (Quintana et al., 2005). Table 1 presents the physicochemical properties of IBP. In the present study, we characterized the shift of bacterial community structure within horizontal subsurface flow (HSSF) CWs planted Typha angustifolia and unplanted control mesocosms receiving IBP-enriched wastewater at a concentration of $250 \mu \mathrm{g} \mathrm{L}^{-1}$ using high-throughput pyrosequencing technology. More specifically, the objectives of this study are to (i) assess the treatment performance within planted and unplanted wetland mesocosms receiving IBP-enriched wastewater; (ii) characterize the shifts in diversity and structure of bacterial community in response to IBP enrichment; and (iii) assess the role that Typha angustifolia plays in the structure shift in bacterial communities receiving IPB-enriched wastewater. To the best of our knowledge, this is the first study to gain a fundamental understanding of the diversity and structure of the microbial community in wetland systems receiving IBP-enriched wastewater using 454 high-throughput pyrosequencing technology.

\section{Materials and methods}

\subsection{Description of the mesocosm-scaled CWs}

Four identical mesocosms including two HSSF CWs planted with cattail (Typha angustifolia) at a density of 15 plant $\mathrm{m}^{-2}$ and two unplanted mesocosms, were set up in parallel at the campus of Nanyang Technological University, Singapore $\left(1^{\circ} 22^{\prime} \mathrm{N}, 130^{\circ} 48^{\prime} \mathrm{E}\right)$. The location is a typical tropical environment and is generally hot and humid year round. The average temperature ranges from $23^{\circ} \mathrm{C}$ to $32{ }^{\circ} \mathrm{C}$. There is no distinct wet/dry season and most rainfall occurs during the northeast monsoon (November to January) when the rainfalls are usually sudden and heavy.

The layout of the HSSF CWs is presented in Supplementary Fig. 1. The four mesocosms were divided into two groups: one was spiked with IBP, while another one was serving as control. Each system was made of fiberglass with the dimensions of $1.2 \mathrm{~m}$ in length, $0.6 \mathrm{~m}$ in width and $0.6 \mathrm{~m}$ in depth. Each mesocosm was filled with $400 \mathrm{~mm}$ thick substrate, which was composed of two layers: a bottom layer of gravel $\left(300 \mathrm{~mm}, \mathrm{D}_{60}=4-10 \mathrm{~mm}\right)$ and an upper layer of loamy sand $\left(100 \mathrm{~mm}, 75 \%\right.$ of sand particles with $\mathrm{D}_{60}=1-2 \mathrm{~mm} ; 23 \%$ silt particles; $2 \%$ clay particles). A horizontal drainage pipe $(0.4 \mathrm{~m}$ long and $50 \mathrm{~mm}$ in diameter) with an outlet valve was located at the lower edge of the mesocosms.

\subsection{System operation and sample collection}

All the systems were acclimatized for three months with daily irrigation of synthetic wastewater to allow the plant roots and biofilm development prior to the study. The synthetic wastewater was obtained by diluting the stock solution to reach initial concentrations of $300 \mathrm{mg} \mathrm{L}^{-1} \mathrm{COD}, 27 \mathrm{mg} \mathrm{L}^{-1} \mathrm{NH}_{4}-\mathrm{N}, 22 \mathrm{mg} \mathrm{L}^{-1} \mathrm{PO}_{4}-\mathrm{P}$, $4 \mathrm{mg} \mathrm{L}^{-1} \mathrm{Fe}^{3+}, 7 \mathrm{mg} \mathrm{L}^{-1} \mathrm{Mg}^{2+}$, and $6 \mathrm{mg} \mathrm{L}^{-1} \mathrm{Ca}^{2+}$. 50-liter of synthetic wastewater was spiked with $12.5 \mathrm{mg}$ of IBP to obtain an influent concentration of $250 \mu \mathrm{g} \mathrm{L}^{-1}$. Batch modes were operated at hydraulic retention time (HRT) of 4-d resulting from a hydraulic loading rate of $2.8 \mathrm{~cm} \mathrm{~d}^{-1}$. Water depth was maintained at $5 \mathrm{~cm}$ below gravel surface.

The experiment lasted 7 months from June to December, 2013. The wastewater effluent samples were collected weekly to determine physicochemical parameters (e.g., DO, conductivity, COD, $\mathrm{NH}_{4}-\mathrm{N}, \mathrm{PO}_{4}{ }^{3-}$, etc.) and IBP concentrations. Soil samples were collected every two months from four different wetland regimes for bacterial community analysis. In both planted and unplanted wetland systems, three bulk soil samples were taken at the depth of 5-10 cm from surface using an auger at random spots and combined in a polyethylene bag. All samples were kept in a cooler with ice packs to inhibit bacterial activity until further reprocessing in the laboratory. At the laboratory, each bag was homogenized manually to mix all three samples for each sampling spot. Any visible plant material was manually removed prior to homogenization. Once mixed, a subsample was taken from each bag and transferred to a microtube $(2 \mathrm{~mL}$ ) for DNA extraction. Tubes were stored at a freezer (at $-80^{\circ} \mathrm{C}$ ) until microbial molecular analysis was conducted.

\subsection{Analytical procedures for water quality parameters and IBP concentration}

Physicochemical parameters were analyzed within $24 \mathrm{~h}$ using spectrophotometer (HACH-DR 3800, USA) based on Standard Methods (APHA, 1998): chemical oxygen demand (COD), ammonium $\left(\mathrm{NH}_{4}-\mathrm{N}\right)$, nitrate $\left(\mathrm{NO}_{3}-\mathrm{N}\right)$ and total phosphorus (TP). 
Table 1

Chemical properties for ibuprofen.

\begin{tabular}{|c|c|c|c|c|c|c|c|}
\hline Compound & CAS number & Use & Chemical structure & Mol. Weight ${ }^{a}$ & $\mathrm{p} K_{\mathrm{a}}{ }^{\mathrm{a}}$ & $\log k_{\mathrm{ow}}{ }^{\mathrm{a}}$ & $\log D_{\text {ow }}$ \\
\hline Ibuprofen & $15687-27-1$ & Analgesic & & 206.29 & 4.91 & 3.97 & 1.68 \\
\hline
\end{tabular}

a The Physical Properties Database (PHYSPROP).

b ChemAxon Marvin Calculator Software was used to calculate $\log D_{\text {ow. }}$.

Dissolved oxygen (DO), $\mathrm{pH}$, and conductivity were measured directly using a portable Multi-Parameter Digital Meter $(\mathrm{HACH}-$ HQ40d, USA).

IBP (99.9\% purity) was obtained from Sigma-Aldrich (Singapore). HPLC-grade acetonitrile, methanol, hexane and ethyl acetate were obtained from Fisher (USA). The solid phase extraction (SPE) cartridges GracePureTM C18 (500 mg, $6 \mathrm{~mL}$ ) were purchased from Grace Davison Discovery Sciences (Belgium).

The concentrations of IBP were analyzed following previously described methodology (Zhang et al., 2012b). SPE was conducted prior to chromatographic analysis. Briefly, $500 \mathrm{~mL}$ of wastewater effluent was filtered through a $0.45 \mu \mathrm{m}$ glass fiber membrane filter (Millipore, USA) and then acidified to $\mathrm{pH} 2$ with hydrochloric acid. The SPE cartridges were conditioned using $5 \mathrm{~mL}$-hexane, $5 \mathrm{~mL}$ ethyl acetate, $10 \mathrm{~mL}$ methanol and $10 \mathrm{~mL}$ of Milli-Q $(\mathrm{pH}=2)$ at a flow rate of $3 \mathrm{~mL} / \mathrm{min}$. Samples were percolated to the SPE cartridges through a Teflon tube at a flow rate of $10 \mathrm{~mL} / \mathrm{min}$. The cartridge filter was then rinsed with methanol:Milli-Q water $=10: 90$, followed by $20 \mathrm{~mL}$ of Milli-Q water $(\mathrm{pH}=2)$. Thereafter the cartridges were allowed to dry for $30 \mathrm{~min}$ and then eluted with $5 \mathrm{~mL}$ ethyl acetate. The extracted solution was then concentrated to ca. $400 \mu \mathrm{L}$ under a gentle nitrogen stream and was then reconstituted to $500 \mu \mathrm{L}$ with methanol.

A Shimadzu Ultra Fast Liquid Chromatography (UFLC) (Shimadzu, Japan) equipped with a quaternary LC-20AD pump, a CTO-20A oven, and a SPD-M20A Diode Array Detector (DAD), was used for chromatographic analysis. Chromatographic separation was carried out using an Inertsil ODS-3 $(4.6 \mathrm{~mm} \times 150 \mathrm{~mm}, 5 \mu \mathrm{m})$ HPLC column protected by a ODS-3 (C18) guard column (Alpha Analytical, Singapore).

IBP removal efficiencies were estimated as the percentage change in concentration after treatment using Eq. (1).

IPB removal efficiency $=\frac{C_{i}-C_{0}}{C_{i}} \times 100 \%$

where $C_{i}=$ IBP concentration in the influent and $C_{0}=$ IBP concentration in the effluent (Fig. 1).

\subsection{DNA extraction and polymerase chain reaction (PCR)}

$0.25 \mathrm{~g}$ of the soil pellet was prepared for DNA extraction. Microbial genomic DNA was extracted using Fast DNA Spin Kit for Soil (MP Biomedicals, USA). DNA products were verified by the $260 / 280$ $\mathrm{nm}$ and 260/230-nm absorption rations, measured by an ND-2000 spectrophotometer (Nanodrop Inc., Wilmington, DE) and agarose gel electrophoresis.

Bacterial 16S ribosomal DNA fragments were amplified in a DNA thermocycler (Eppendorf, Germany) using universal bacterial primers that target the V1-V3 of the 16S rRNA gene: Gray 28F (5'-GAGTTTGATCNTGGCTCAG-3') and Gray 519R (5'GTNTTACNGCGGCKGCTG-3') (Baker et al., 2003). The PCR reaction system contained: $2 \mu \mathrm{l}$ of template DNA, $10 \mu \mathrm{M}$ each primer, $2.5 \mathrm{mM} \mathrm{MgCl}_{2}, 200 \mu \mathrm{M}$ dNTP, $5 \mu \mathrm{l}$ of $10 \times$ PCR buffer, $0.5 \mathrm{U}$ of Taq DNA polymerase (Fisher BioReagents, USA). PCR amplification was performed with an initial denaturation at $94^{\circ} \mathrm{C}$ for $3 \mathrm{~min}$ and 20 cycles at $94^{\circ} \mathrm{C}$ for $1 \mathrm{~min}$, followed by an annealing step at $55^{\circ} \mathrm{C}$ for $45 \mathrm{~s}, 72^{\circ} \mathrm{C}$ for $45 \mathrm{~s}$, and a final extension at $72{ }^{\circ} \mathrm{C}$ for $10 \mathrm{~min}$.

\subsection{Processing of pyrosequencing data}

The DNA samples were submitted to Research and Testing Laboratory (Lubbock, TX) for bacterial tag-encoded FLX amplicon pyrosequencing (bTEFAP) (Dowd et al., 2008). bTEFAP yield a total of 24,348 sequences with average length of $480 \mathrm{bp}$ and average quality score of 35 . The sequences were processed using the MOTHUR bioinformatics software package (version 1.3) (Schloss et al., 2009). The raw reads were first trimmed for adapters, barcodes and primers. The trimmed sequences were screened for length ( minimum $=200$ ), homopolymers ( maximum $=8$ ), ambiguous bases ( 0 allowed) and quality (average $=25$ ). Sequences that passed the above criteria were then aligned against the nonredundant SILVA database (Quast et al., 2013). Chimeras were filtered out using UCHIME within MOTHUR followed by taxonomic classification of bacterial sequences using Ribosomal Database Project (RDP) Training Set as reference, with a confidence value of $80 \%$. Sequences with similarities below these criteria were classified into unidentified groups for each taxonomic rank. A distance matrix was constructed at a $3 \%$ dissimilarity. After all the sequence processing, a total of 20,482 remaining sequences were clustered into operational taxonomic units (OTUs) using the furthest neighbor method. The closest relative for representative sequence of each OTU was identified using RDP Seqmatch and the phylogenetic tree was constructed using MEGA6 with bootstrap calculation using the p-distance model.

\subsection{Statistical analysis}

To avoid unequal sampling bias, the libraries were normalized by randomization to the smallest library for computing diversity indices. R Programme (v 2.14.2, http://www.r-project.org/) was used for the calculation of relative abundance. $\alpha$-Diversity indices (Shannon-Wiener indices $\left(H^{\prime}\right)$, Simpson's Diversity indices and Shannon evenness indices $\left(J^{\prime}\right)$ ) of each sample were calculated using MOTHUR. To visualize the effect of IBP on the bacterial community profile, nonmetric multidimensional scaling (NMDS) was created using Bray-Curtis similarity matrices with PRIMER-E (Version 6). For differentiating the statistical differences in the contaminant removal efficiencies and bacterial diversity indices, discriminant function analysis was performed. One-way ANOVA (at a significance level of 0.05) was applied using SPSS software package (SPSS 

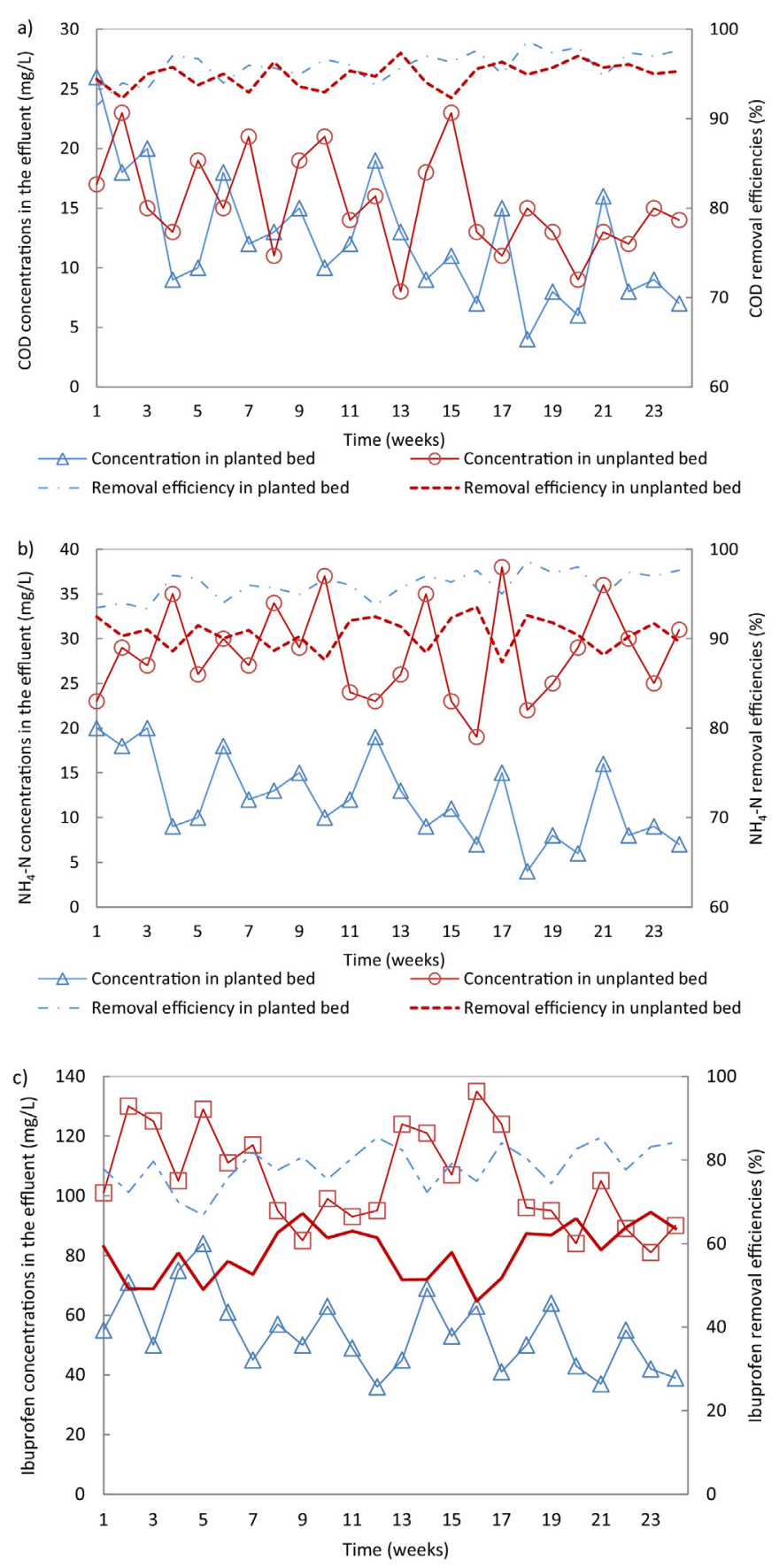

$\triangle$ Concentration in planted bed $\quad \square$ Concentration in unplanted bed

- - - Removal efficiency in planted bed _ Removal efficiency in unplanted bed

Fig. 1. Effluent concentrations in the planted and unplanted wetland mesocosms operated for 24 weeks. (a) COD; (b) NH4-N; and (c) ibuprofen.

V15.0). For all ANOVA tests it was verified that the variables were distributed normally.

\section{Results and discussion}

\subsection{Performance of wetland systems}

The average concentrations of physicochemical parameters in the influent and effluent were shown in Table 2. As expected, the overall average removal efficiencies of COD were significantly $(P \leq 0.05)$ enhanced in the planted beds compared to those in the unplanted beds (Fig. 2a), even though the difference in removal

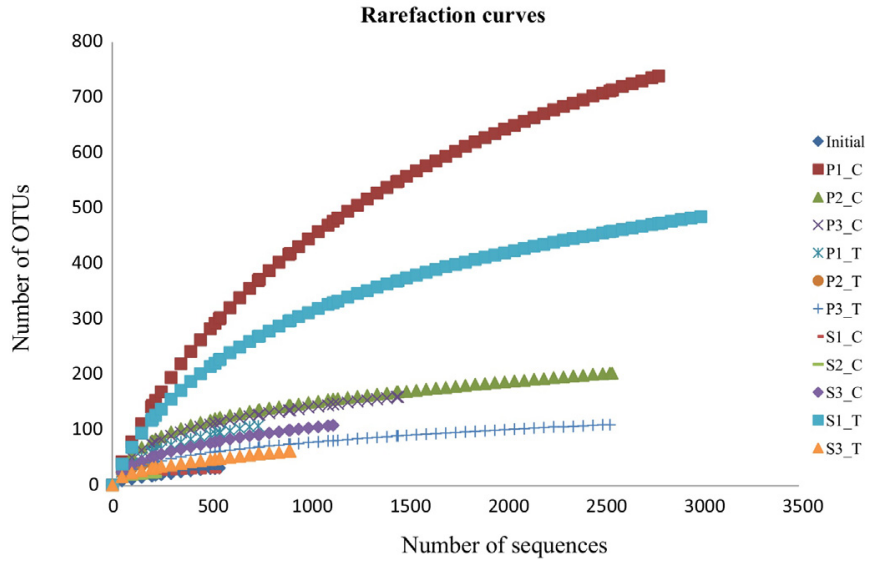

Fig. 2. Rarefaction curves of sequences of bacterial 16S rRNA genes from control and treatment, calculated by MOTHUR with a 3\% distance cutoff. (i) Letter "P" represents planted beds; (ii) Letter "S" represents unplanted beds; (iii) Letter "T" represents treatment; (iv) Letter " $C$ " represents control; and (v) Number "1", "2", and " 3 " represent the sampling time.

efficiency for the planted beds (96.0\%) was only slightly better than that for the unplanted (90.6\%). This finding is in good agreement with Caselles-Osorio and Garcia (2007) who found that the presence of plants clearly had a significant impact on the removal efficiency of COD, and attributed this impact to either the convective transport of oxygen or indirectly to increased evapotranspiration rates that increased fluctuations in water levels. The presence of Typha angustifolia also significantly $(P \leq 0.05)$ enhanced removal of ammonium in the planted beds (80.2\%) compared to unplanted beds (48.7\%) (Fig. 2b).

Similarly, significantly $(P \leq 0.05)$ higher removal efficiencies of IBP in the planted beds (78.5\%) was observed compared to those in the unplanted beds (57.9\%) (Fig. 2c). This finding is consistent with Verlicchi and Zambello (2014) who reviewed the occurrence and fate of 137 micropollutants in wetland systems, and reported that mean removal efficiencies of IBP were $85 \%$ in vertical subsurface flow CWs, while in HSSF CWs the mean removal efficiencies were $52-60 \%$. With relatively high $\log K_{\text {ow }}$ value of 3.97 , the electrostatic repulsion of its negatively charged surface by the negatively charged sludge, resulted in weak adsorption of IBP to the sludge (Radjenović et al., 2009). Thus, microbial degradation, not adsorption, may be a main mechanism to exploit for IBP removal (Quintana et al., 2005). Winker et al. (2010) investigated the potential of Ryegrass for uptake of IBP and reported that IBP was not detected in the soil or in any plant parts after three months, and further confirmed the main elimination pathway for IBP was biodegradation. Similarly, Hijosa-Valsero et al. (2010) assessed the ability to remove PhACs of three different full-scale hybrid pond-CW systems. The removal efficiencies of IBP were reported to be $42-89 \%$, and large proportions of IBP were removed in the HSSF CWs compared to pond systems. The author indicated that this different behavior might be related to redox microenvironmental conditions and the subsystem planted with $T$. latifolia, which plays a notable role in the IBP removal.

\subsection{Diversity of microbial communities}

A 97\% similarity cut-off was used to delineate OTUs in the downstream analysis using the pyrosequencing approach. Among the large diversity of sequences in the 16S rRNA gene libraries in the present study, 1242 OTUs have been identified at a $3 \%$ distance across the 12 samples and 218 OTUs were found to be shared among two or more samples. Compared to conventional molecular methods which may have insufficient resolutions to characterize the 
Table 2

Average concentrations of physicochemical parameters in the influents and effluents in wetland systems (“ \pm ” represents standard deviation).

\begin{tabular}{|c|c|c|c|c|c|}
\hline & \multirow[t]{3}{*}{ Inlet } & \multicolumn{4}{|l|}{ Outlet } \\
\hline & & \multicolumn{2}{|l|}{ HSSF CWs } & \multicolumn{2}{|l|}{ Sand filters } \\
\hline & & Control & Treatment & Control & Treatment \\
\hline $\mathrm{pH}$ & $7.7 \pm 0.2$ & $6.9 \pm 0.1$ & $6.6 \pm 0.2$ & $6.5 \pm 0.2$ & $6.3 \pm 0.3$ \\
\hline Conductivity $\left(\mathrm{S} \mathrm{m}^{-1}\right)$ & $457 \pm 13$ & $423 \pm 36$ & $405 \pm 47$ & $391 \pm 51$ & $479 \pm 63$ \\
\hline $\mathrm{DO}\left(\mathrm{mg} \mathrm{L}^{-1}\right)$ & $7.6 \pm 0.5$ & $4.0 \pm 1.6$ & $3.7 \pm 2.0$ & $3.1 \pm 0.9$ & $2.9 \pm 1.4$ \\
\hline $\mathrm{NO}_{3}-\mathrm{N}\left(\mathrm{mg} \mathrm{L}^{-1}\right)$ & $9.3 \pm 0.9$ & $1.5 \pm 0.2$ & $1.1 \pm 0.4$ & $4.3 \pm 0.7$ & $3.1 \pm 0.4$ \\
\hline $\mathrm{PO}_{4}{ }^{3-}\left(\mathrm{mg} \mathrm{L}^{-1}\right)$ & $22 \pm 1.7$ & $8.4 \pm 2.6$ & $7.3 \pm 2.1$ & $11.6 \pm 3.7$ & $12.4 \pm 3.7$ \\
\hline
\end{tabular}

microbial communities, 454 high-throughput sequencing technology is an effective method for better understanding of the diversity of microorganisms in various environments (Ma et al., 2013; Zhang et al., 2012c).

On the basis of the OTU number (Table 3), OTUs from the planted control bed ranged from 75.3 to 145.0 , while the OTU numbers in the planted IBP-treatment beds were in the range of 41.6-60.4, indicating that planted control mesocosm showed higher richness compared to the treatment beds. A similar trend was also observed in the unplanted beds. This finding was further supported by calculation of the Shannon-Weiner's index $\left(H^{\prime}\right)$, which is commonly used to characterize species diversity and accounts for both abundance and evenness of the species present. Considering the fact that $H^{\prime}$ of control beds was significantly larger $(P \leq 0.05)$ than IBP-enriched beds, it could be inferred that the enriched OTU in the control community was distributed more evenly than those in the IBP-enriched beds. Many studies have calculated Shannon diversity index $\left(H^{\prime}\right)$ in aquatic systems and values typically range from 0.5 to 5 , with values of 0.5-2.0 implying low diversity and values of 2.0-5.0 indicating high diversity (Garrido et al., 2014). In this study, the majority of $H^{\prime}$ were higher than 2.0 , with a range of $1.59-5.60$, suggesting a relatively high $H^{\prime}$ value and wide range of diversity for the present treatment wetlands compared to previous studies on CWs (2.0-3.8 in Arroyo et al. (2013); 1.74-2.93 in Peralta et al. (2013)).

Rarefaction curves, which describe the occurrence of novel OTUs as a function of sampling effort for OTUs at a 0.03 distance cutoff, are shown in Fig. 2 with sequence number of $16 \mathrm{~S}$ rRNA plotted as a function of unique OTUs among treatment and control regimes. For most of rarefaction curves shown in Fig. 2, their flat slopes indicate that a large fraction of the species diversity has been covered and a reasonable number of individual samples have been taken.

\subsection{Similarity of microbial communities}

In order to better understand the phylogenetic profiles corresponding to the microbial communities of each CW unit at each sampling time, a cluster analysis based on pyrosequencing taxonomy was conducted using Bray-Curtis similarity was performed (Fig. 3). Using 0.6 as a bench-mark (McLellan et al., 2010), for the planted mesocosms, the similarity value for the IBP-treated mesocosms as compared to the control beds was within 0.6 (with the single exception of the first IBP-treated sample), implying that

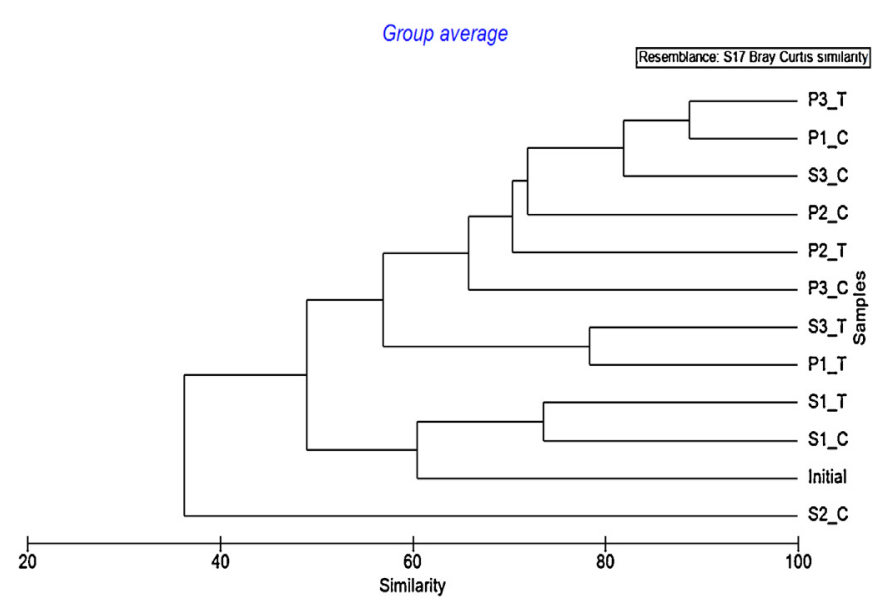

Fig. 3. Cluster analysis based on pyrosequencing taxonomy was conducted using Bray-Curtis similarity. (i) Letter "P" represents planted beds; (ii) Letter "S" represents unplanted beds; (iii) Letter "T" represents treatment; (iv) Letter " $\mathrm{C}$ " represents control; and (v) Number " 1 ", " 2 ", and " 3 " represent the sampling time.

considerable similarity was observed between the IBP-enriched and control mesocosms. In contrast, for the unplanted beds, this similarity value of 0.6 between treatment and control was only observed in the first sample. Besides, the dissimilarity among the samples from IBP-enrichment unplanted beds increased with time. This finding indicated that IBP-exposure might have greater impact on the unplanted mesocosms than that in the planted beds, and the aquatic plants might have played a role in shaping the structure of the bacterial community with IBP disturbance.

The NMDS presented in Fig. 4 allows visualization of how the samples are plotted together and provides an insight in the level of dispersion between them, facilitating the interpretation of the results previously addressed in the dendrograms. The difference between the bacterial assemblages of each unit is evident, reinforcing the effect of the IBP-exposure and the presence of the plant on the modification of bacterial community.

\subsection{Composition of microbial community}

The relative abundance of bacteria taxonomic groups is shown in Fig. 5. In the present study, in total, 20 phyla comprising 265

Table 3

Summary of sequencing data for OTUs, Chao richness, Shannon evenness indices $\left(J^{\prime}\right)$, and Shannon-Wiener indices $\left(H^{\prime}\right)$.

\begin{tabular}{|c|c|c|c|c|c|c|c|c|c|c|c|c|c|}
\hline & \multirow{3}{*}{$\begin{array}{l}\text { Soil } \\
\text { Initial } \\
\text { June }\end{array}$} & \multicolumn{6}{|c|}{ HSSF CWs } & \multicolumn{6}{|c|}{ Sand Filters } \\
\hline & & \multicolumn{3}{|l|}{ Control } & \multicolumn{3}{|c|}{ Treatment } & \multicolumn{3}{|c|}{ Control } & \multicolumn{3}{|c|}{ Treatment } \\
\hline & & Aug & Oct & Dec & Aug & Oct & Dec & Aug & Oct & Dec & Aug & Oct & Dec \\
\hline Observed OTUs & 17.9 & 145 & 81.6 & 75.3 & 60.4 & 42.0 & 41.6 & 20.0 & 16.3 & 51.6 & 11.9 & - & 31.8 \\
\hline Chao richness & 43.3 & 510 & 129 & 119 & 102 & 64.8 & 65.6 & 30.9 & 34.1 & 89.7 & 24.9 & - & 54.4 \\
\hline Shannon evenness index $\left(J^{\prime}\right)$ & 0.68 & 0.95 & 0.92 & 0.90 & 0.73 & 0.88 & 0.81 & 0.91 & 0.53 & 0.85 & 0.79 & - & 0.66 \\
\hline Shannon-Wiener index $\left(H^{\prime}\right)$ & 2.06 & 5.60 & 4.35 & 4.19 & 3.36 & 3.40 & 3.19 & 4.99 & 1.59 & 3.55 & 2.43 & - & 2.47 \\
\hline
\end{tabular}

Note: To avoid unequal sampling bias, the libraries were normalized by randomization to the smallest library for computing OTU number and diversity indices. 


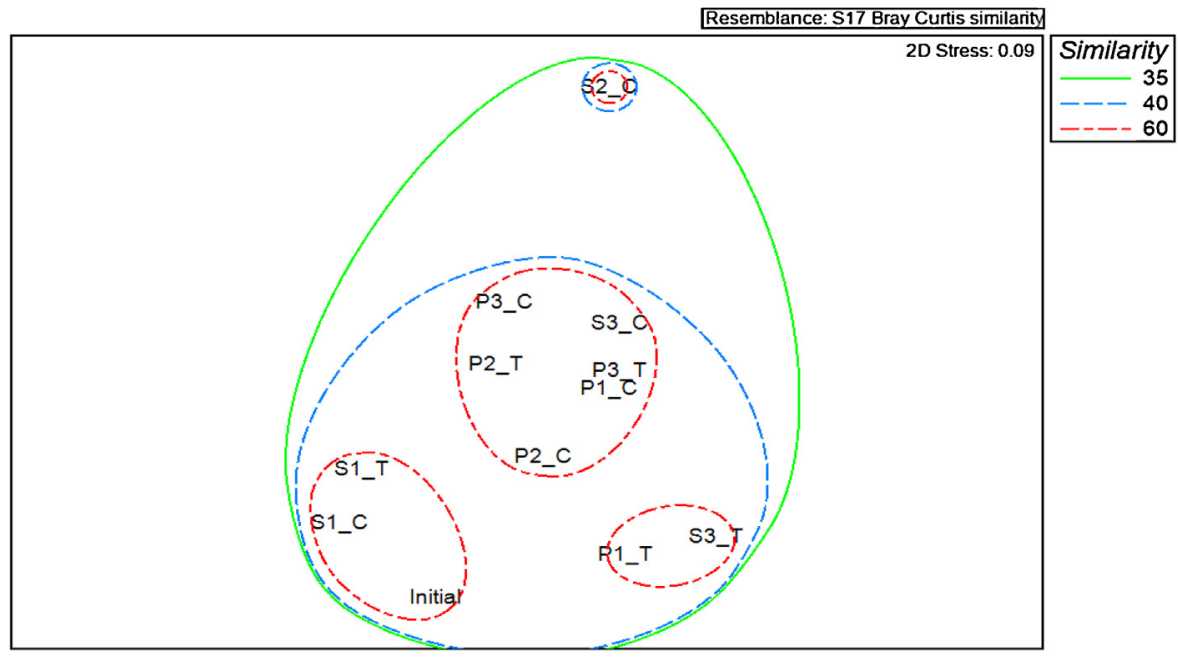

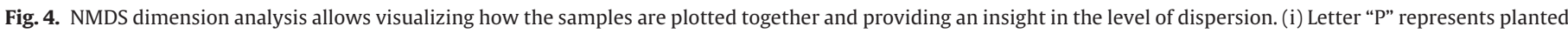

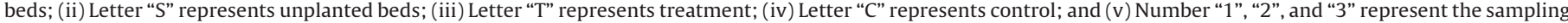
time.

A
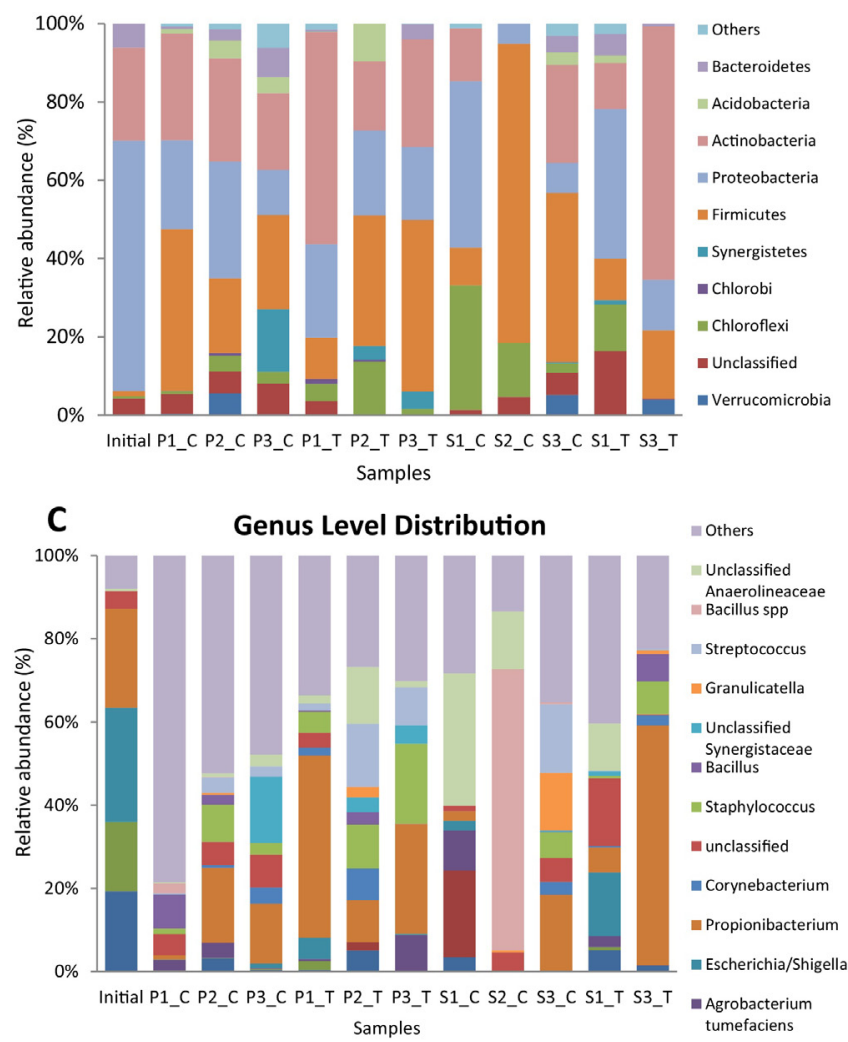

B

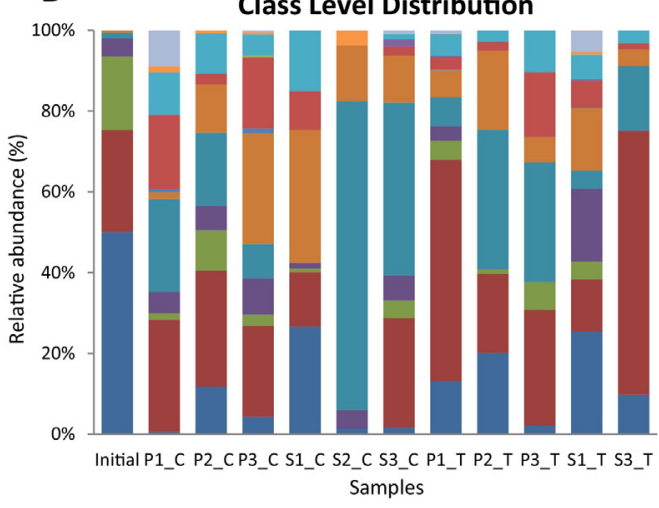

- Epsilonproteobacteria

- Deltaproteobacteri

E Unclassified Proteobacteria

negativicutes

mErysipelotrichia

- Clostridia

- Unclassified Firmicutes

nothers

=Bacilli

m unclassified

= Betaproteobacteria

- Actinobacteria

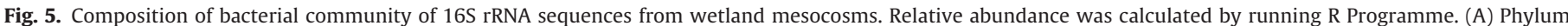

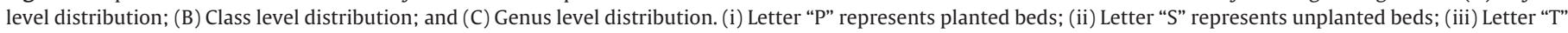
represents treatment; (iv) Letter " $C$ " represents control; and (v) Number " 1 ", " 2 ", and " 3 " represent the sampling time.

genera were identified. Firmicutes (averaging 27.6\%) represented the most abundant phylum, followed by Actinobacteria (26.0\%) and Proteobacteria (24.9\%), making up 57-95\% of the 16S rDNA sequences. These phyla were the predominant bacteria have been reported to be typical flora that could adapt best in response to changes of the external environment in wetland systems (Ahn et al., 2007; Calheiros et al., 2009). Ahn et al. (2007) applied length heterogeneity PCR (LH-PCR) fingerprinting based on the 16S rRNA gene to characterize microbial communities in planted and unplanted constructed wetland microcosms with different phosphorus loading. The authors indicated that the microbial community of the wetland sediment was dominated by $\alpha$-proteobacteria (48-60\% of clones), followed by Actinobacteria and Firmicutes. The other predominant phyla in the present study were Chloroflexi (7.3\%), Bacteroidetes (2.7\%), Synergistetes (2.1\%), and Acidobacteria (2.0\%). It was also noted that besides the dominant microbes, as 
Table 4

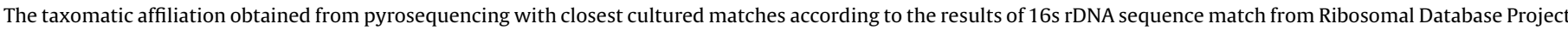
(RDP).

\begin{tabular}{|c|c|c|c|c|c|}
\hline Taxonomic group & Phylogenetic affiliation at genus level & Closest match & NCBI accession no. & Similarity (\%) & Relative abundance (\%) \\
\hline Firmicutes & Unclassified Bacillales & Bacillus spp. & AM690038 & 97 & 5.9 \\
\hline Firmicutes & Staphylococcus & Staphylococcus epidermidis & AY730712 & 100 & 5.2 \\
\hline Firmicutes & Streptococcus & Streptococcus dysgalactiae & AB008926 & 100 & 4.1 \\
\hline Firmicutes & Bacillus & Bacillus vireti & EU221372 & 100 & 1.7 \\
\hline Firmicutes & Granulicatella & Granulicatella para-adiacens & AY879298 & 100 & 1.5 \\
\hline Firmicutes & Unclassified Clostridiales & Uncultured bacterium & JN223441 & 91.2 & 1.4 \\
\hline Firmicutes & Unclassified Clostridiaceae_1 & Clostridium spp. & AY949856 & 97 & 1.1 \\
\hline Firmicutes & Sporosaricina & Sporosaricina globispore & AB681045 & 97 & 0.8 \\
\hline Firmicutes & Clostridium_sensu_stricto & Clostridium chromiireducens & AY228334 & 97 & 0.5 \\
\hline Firmicutes & Unclassified Ruminococcace & Uncultured bacterium & AB853909 & 85.6 & 0.5 \\
\hline Firmicutes & Unclassified Planococcaceae_incertae_sedis & Lysinibacillus massiliensis & AB299159 & 100 & 0.3 \\
\hline Firmicutes & Acetobacterium & Acetobacterium spp. & HQ012835 & 96 & 0.3 \\
\hline Firmicutes & Lactobacillus & Lactobacillus coryniformis & AJ575741 & 100 & 0.2 \\
\hline Actinobacteria & Propionibacterium & Propionibacterium acnes & AB108480 & 100 & 18.5 \\
\hline Actinobacteria & Corynebacterium & Corynebacterium segmentosum & X84437 & 100 & 1.7 \\
\hline Actinobacteria & Mycobacterium & Mycobacterium moriokaense & AJ429044 & 100 & 0.5 \\
\hline Actinobacteria & Unclassified Micromonosporaceae & Micromonospora spp. & JQ864434 & 93 & 0.3 \\
\hline Actinobacteria & Unclassified Microbacteriaceae & Microbacterium spp. & KC505174 & 97 & 0.3 \\
\hline Actinobacteria & Micrococcus & Micrococcus Luteus & AF057289 & 100 & 0.1 \\
\hline$\gamma$-Proteobacteria & Escherichia/Shigella & Escherichia coli & AP009048 & 99 & 4.3 \\
\hline$\gamma$-Proteobacteria & Unclassified Enterobacteriaceae & Escherichia coli & AB035920 & 100 & 3.2 \\
\hline$\alpha$-Proteobacteria & Unclassified Rhizobiales & Agrobacterium tumefaciens & AJ389907 & 100 & 2.3 \\
\hline$\gamma$-Proteobacteria & Serratia & Serratia quinivorans & AJ233435 & 100 & 2.0 \\
\hline$\beta$-Proteobacteria & Unclassified Betaproteobacteria & Uncultured bacterium & GQ093524 & 100 & 1.7 \\
\hline$\alpha$-Proteobacteria & Grevundimonas & Grevundimonas bullata & AJ717390 & 100 & 1.1 \\
\hline$\alpha$-Proteobacteria & Unclassified Proteobacteria & Uncultured bacterium & EU133433 & 93.3 & 0.6 \\
\hline$\gamma$-Proteobacteria & Pseudomonas & Pseudomonas oryzihabitans & HM755542 & 100 & 0.4 \\
\hline$\gamma$-Proteobacteria & Enhydrobacter & Uncultured bacterium & GQ007555 & 100 & 0.4 \\
\hline$\delta$-Proteobacteria & Unclassified Polyangiaceae & Uncultured bacterium & JQ408113 & 86.6 & 0.4 \\
\hline$\beta$-Proteobacteria & Oxalobacter & Naxibacter indica & EF199744 & 99 & 0.3 \\
\hline$\alpha$-Proteobacteria & Acetobacter & Acetobacter peroxydans & AB665082 & 100 & 0.3 \\
\hline$\alpha$-Proteobacteria & Brevundimonas & Brevundimonas intermedia & AJ007802 & 100 & 0.1 \\
\hline Chloroflexi & Unclassified Anaerolineaceae & Uncultured bacterium & HM312380 & 75.5 & 6.6 \\
\hline Synergistetes & Unclassified Synergistaceace & Uncultured bacterium & AF323769 & 91.1 & 2.1 \\
\hline Bacteroidetes & Unclassified Bacteroidetes & Uncultured bacterium & HQ183932 & 97.1 & 1.2 \\
\hline Verrucomicrobia & Optitutus & Uncultured bacterium & DQ404823 & 95.6 & 1.1 \\
\hline Nitrospirae & Nitrospira & Nitrospira spp. & AJ224039 & 96 & 0.02 \\
\hline
\end{tabular}

many as $4.6 \%$ of total sequences could not be assigned to any phylum.

At the class level, a total of 46 bacterial taxa were found and only one was shared by all the samples, implying relatively rare core populations in the microbial community. The most predominant bacteria were affiliated with Actinobacteria (26.0\%), Bacilli (20.9\%), $\gamma$-Proteobacteria (13.1\%), Anaerolineae (6.6\%), Clostridia (6.3\%), $\alpha$ Proteobacteria (5.6\%), and $\beta$-Proteobacteria (4.3\%) (Fig. 5B). Among the assigned 265 taxa at genus level, the most abundant genera were affiliated with Propionibacterium sp. (18.5\%), unclassified Anaerolineaceae (6.6\%), Bacillus sp. (5.9\%), Staphylococcus sp. (5.2\%), Escherichia/Shigella (4.3\%), Streptococcus sp. (4.1\%), and Escherichia sp. (3.2\%) (Fig. 5C). Table 4 shows the taxonomic affiliation obtained from pyrosequencing analysis with the closest cultured matches according to the results of 16s rDNA sequence match from RDP.

\subsection{The impacts of macrophytes on the microbial community}

In the present study, the soil samples from planted wetland mesocosms exhibited a taxonomic profile that differed from those in unplanted beds. A remarkable enhancement of specific taxonomic groups in the planted beds as compared to the unplanted mesocosms was observed regardless of IBPenrichment. At the class level, for both control and IBP-treatment systems, Clostridia (12.9\% and 7.1\%), $\alpha$-Proteobacteria $(8.6 \%$ and $6.2 \%), \beta$-Proteobacteria ( $4.8 \%$ and $4.3 \%$ ) exhibited a remarkable increase in the planted beds, compared to unplanted beds $(3.9 \%$ and $4.1 \%$ for Clostridia; $5.4 \%$ and $4.6 \%$ for $\alpha$-Proteobacteria; $4.8 \%$ and $2.2 \%$ for $\beta$-Proteobacteria) (Supplementary Fig. $1 \mathrm{~A}-\mathrm{C}$ ). Even in the control mesocosms, the most predominant taxa
Actinobacteria showed significant dissimilarity between planted (26.4\%) and unplanted (13.5\%) beds. In the IBP-treatment system, Bacilli accounted for $23.8 \%$ of the total sequences, while the value was $10.3 \%$ in the unplanted beds. The cluster analysis based on Bray-Curtis similarity (Fig. 3) also clearly showed a considerable similarity between the IBP enriched and control planted beds, while for the unplanted beds, the dissimilarity among the samples increased with time. Furthermore, according to Hooper et al. who suggested a positive effect of diversity on ecosystem function, the higher bacterial diversity observed in the planted mesocosms (suggested by higher Shannon-Wiener indices $\left(H^{\prime}\right)$ ) indicated more ecosystem functions, compared to unplanted beds.

It is generally accepted that planted wetlands outperform unplanted controls in phytoremediation, mainly because of the release of oxygen from the plant internal root zones (Stottmeister et al., 2003). Since biochemical processes in wetland systems are distinguished by different redox potentials, which determine to a great extent the potential for the occurrences of microbial organisms and concurrently influence the spatial distribution of specific microbial biomass (Truu et al., 2009). Additionally, the macrophytes may promote soil remediation by stimulating the diversity of rhizosphere-inhabiting microorganisms, which contribute to the removal of organic contaminants indirectly through the interactions between plant and microorganisms (Healy et al., 2007). This finding is in good agreement with previous studies (Calheiros et al., 2009; Li et al., 2008), confirming that the presence of macrophytes may have vital impact on the microbial community, and planted wetlands may be more robust and buffered against significant shifts in microbial composition in response to various disturbances. 


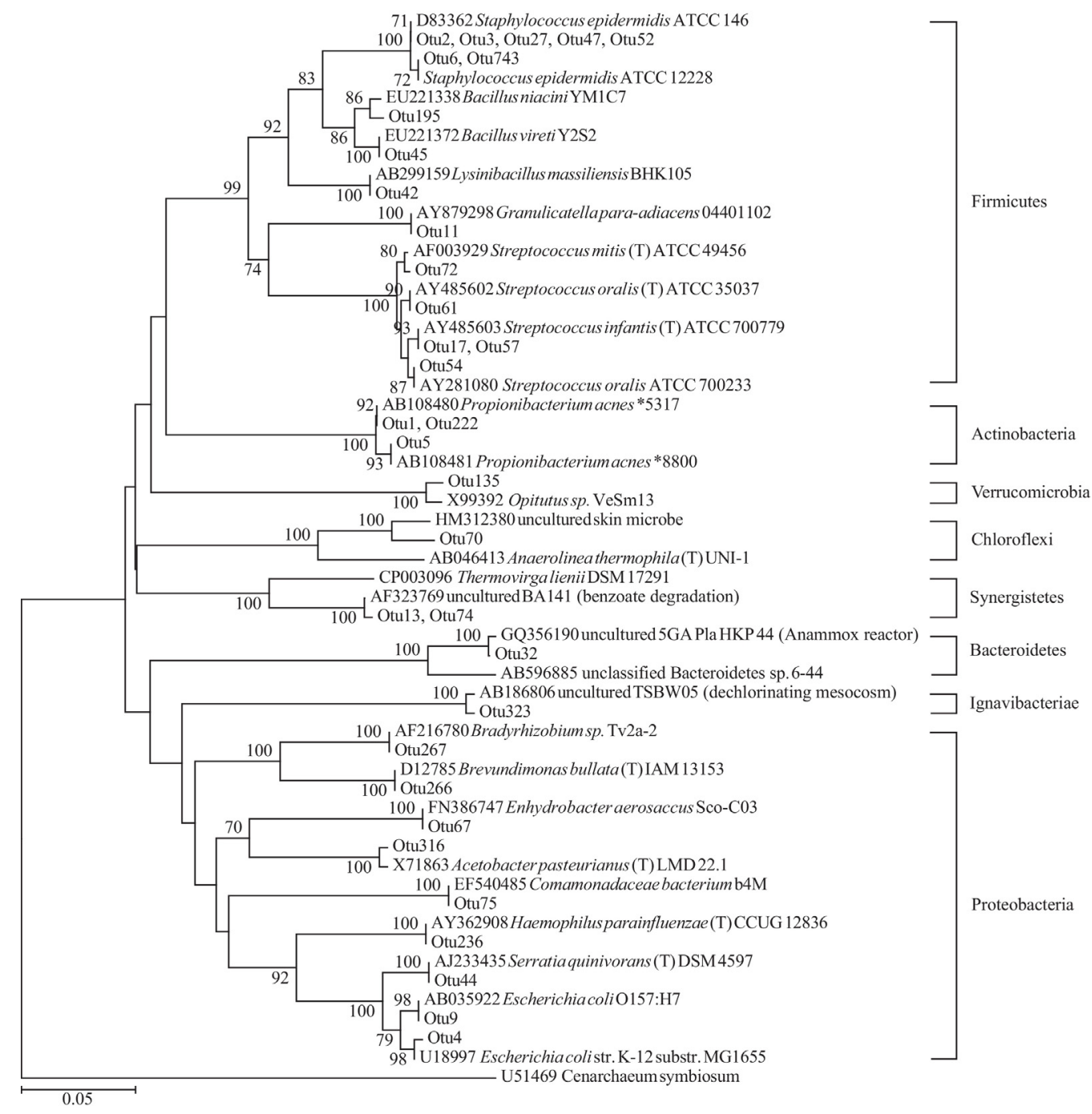

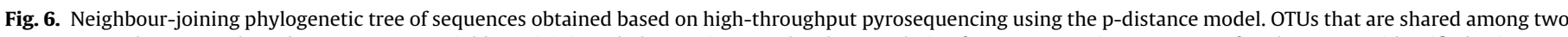

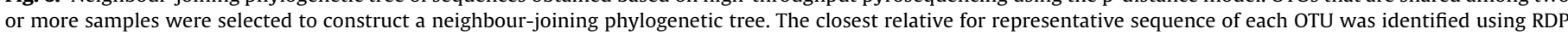

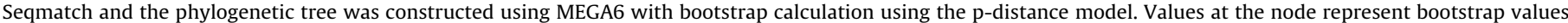
(only values above 70 are shown).

\subsection{Response of bacterial community to IBP enrichment}

Microorganisms play key roles in most of the biogeochemical cycles, making them key components of any phytoremediation processes in wetland systems (Ligi et al., 2014; Sleytr et al., 2009; Truu et al., 2009). Bacteria are distributed in the soil according to their adaptive capacity and permanence under the specific soil conditions (Ruiz et al., 2002). They usually form a robust community capable of surviving and functioning under extremes of temperature, water availability, $\mathrm{pH}$, energy resources, nutrient availability and salt concentration. The shift of the bacterial community induced by IBP enrichment might have been attributed to the selection and adaption of microorganisms to the contaminant exposure. It is highly possible that the IBP-enriched soil may have selected a restricted group of bacteria that were able to best survive in the disturbed condition, and the related alteration in microbial structure reflected a response of the microbial community to the disturbance of a balanced ecosystem. The high removal performances observed throughout the study suggested that the selected microbial communities were able to tolerate and participate in the IBP degradation.

A distinct microbial community profile after IBP enrichment was observed. All the three predominant phyla Proteobacteria,
Actinobacteria and Firmicutes showed increase in relative abundance in the IBP-enriched planted beds compared to the control (Fig. 5A). In contrast, for the unplanted beds, the most predominant bacteria shifted from Actinobacteria (38.3\%), Proteobacteria (25.6\%), and Firmicutes (14.0\%) to Firmicutes (43.0\%), Proteobacteria (18.4\%) and Actinobacteria (12.8\%), implying that unplanted beds were more vulnerable and susceptible to IBP-enrichment compared to planted beds.

At class level (Fig. 5B), the predominant taxa Actinobacteria, which are considered as the most versatile and efficient degraders of diesel oil, phenol and polycyclic aromatic hydrocarbons (Zhang et al., 2012a), exhibited a marked increase (33.1\% and $38.3 \%$ ) in the IBP-treated mesocosms compared to the control $(24.4 \%$ and $12.8 \%)$. Higher abundance of Bacilli was also observed in the planted IBP-treated mesocosms (22.2\%) compared to the planted control (15.5\%). Bacilli has been widely reported to be highly efficient in the removal of nutrients and concentrated organic compounds in previous studies (Seong et al., 2007; Teixeira et al., 2010). Moreover, it is worth noting the fact that aerobic Bacilli (20.9\%) was more dominant than strictly anaerobic Clostridia (6.3\%), implying that wetland systems entailed microenvironment and several biogeochemical conditions might have coexisted. $\gamma$-Proteobacteria accounted for $13.1 \%$ of all the sequences and exhibited an increasing trend in 
both planted (11.1\%) and unplanted mesocosms (16.4\%) after the IPB exposure, compared to control (5.0\% in the planted and 9.8\% in the unplanted beds). $\gamma$-Proteobacteria has been reported to be significantly increased when the nonsteroidal anti-inflammatory drug diclofenac, was added to the reactor (Lawrence et al., 2007). With respect to the unplanted mesocosms, other populations were increasing, including $\beta$-Proteobacteria, Clostridia and $\delta$ Proteobacteria in the unplanted beds, implying the microbial community structure was dynamically influenced by addition of IBP.

As an indicator of resistance, the three genera that exhibited the greatest increases in relative abundances in the planted mesocosms after IBP exposure were closely affiliated with Propionibacterium acnes (26.8\%), Staphylococcus epidermidis (11.7\%), and Streptococcus dysgalactiae (8.6\%), compared to the control (11.1\%, $4.5 \%$ and 2.1\%, respectively) (Fig. 5C; Supplementary Fig. 1D-F). The ability of Propionibacterium for degradation of toxic compound is correlated to the presence of lipases activity, and these hydrolytic activities contribute to increase of its adaptive capacity, and allow the colonization of habitats rich in complex nutrients where other microorganisms using simpler substrates could not grow (Bell et al., 1998). Additionally, Serratia quinivorans, Corynebacterium segmentosum, Esherichia coli also showed increase after IPB treatment, suggesting that these highly prevalent genera were apparently well adapted to IBP-exposure and might have contributed to the IBP biodegradation. Marked differences in the OTU presented for the control and IBP-treated mesocosms can also be observed in a neighbor-joining phylogenetic tree, which was constructed using the $p$-distance model based on the 454 pyrosequencing data (Fig. 6). The most responsive group of OTUs are OTU $1 \#, 5 \#$ and $222 \#$, which are identified as species Propionibacterium acnes. In the planted mesocosms, these OTUs consisted of $11 \%$ of the community in control mesocosms, while the values were increased by more than 2 -fold in the IBP-enriched mesocosms. Similarly, the relative abundance of these OTUs increased more than 5-fold from $5.7 \%$ to $30.7 \%$ in the unplanted mesocosms. Seven OTUs (OTU 2\#, 3\#, 6\#, 27\#, 47\#, 52\#, and 743\#) that were identified as Staphylococcus epidermidis, were 2.9 times (planted bed) and 3.2 times (unplanted bed) more dominant in the IBP-treated mesocosms as compared to the control.

On the contrary, the genera that decreased notably in the planted mesocosms after IBP-enrichment were Unclassified Synergistaceace (5.3\%) and Granulicatella para-adiacens (0.8\%), compared to the control beds (2.6\% and $0.2 \%$, respectively). In particular, Bacillus sp., Opitutus sp., unclassified Clostridiales became even undetectable at the end of experiment, suggesting that these genera were most sensitive under IPB-load condition and may have contributed to the decrease in diversity of bacterial community. Disturbance from pollutants reduced the number of active microbial taxa to only those that were pollutant-tolerant; therefore, inadaptable microorganisms might have no longer been a relevant component of the community and the selected species may act synergistically with plants to affect the fate of IBP by biodegradation. In Fig. 6, OTUs (OTU 195\# and 45\#) belonging to Bacillus spp., decreased to below detection level in the ibuprofen-enriched planted bed. In addition to OTU 11\# belonging to Granulicatella para-adiacens, another 5 OTUs (OTU 17\#, 54\#, 57\#, 61\# and 72\#), identified to be close relatives of Streptococcus spp., were also found to be more dominant in the planted mesocosoms treating IBPenriched wastewater.

\section{Conclusions}

Bacterial community play a vital role in many biogeochemical processes that promote ecological functions and maintenance in constructed wetlands. In this study, we used 454 high throughput pyrosequencing technology to characterize bacterial communities of wetland mesocosms enriched with ibuprofen. The results showed that constructed wetlands have the capacity to treat pharmaceutical wastewater. Overall diversity of the bacterial community was reduced in the presence of ibuprofen. The taxonomic information revealed that the structure of bacterial communities with IBP-enrichment differed from the control. Compared to the planted mesocosms, unplanted bacterial communities in the ibuprofen-treated wetland exhibited less similarity to the control, implying that the presence of the higher macrophytes did appear to exert a remarkable effect on the community composition after IBP-enrichment. The high IBP removal efficiencies observed throughout the study confirmed that the selected microbial community is able to tolerate and participate in the IBP degradation.

\section{Appendix A. Supplementary data}

Supplementary data associated with this article can be found, in the online version, at http://dx.doi.org/10.1016/j.ecoleng.2015.12. 043.

\section{References}

Ahn, C., Gillevet, P.M., Sikaroodi, M., 2007. Molecular characterization of microbial communities in treatment microcosm wetlands as influenced by macrophytes and phosphorus loading. Ecol. Indic. 7, 852-863.

Arroyo, P., Ansola, G., Miera, L.E.S.D., 2013. Effects of substrate, vegetation and flow on arsenic and zinc removal efficiency and microbial diversity in constructed wetlands. Ecol. Eng. 51, 95-103.

Baker, G.C., Smith, J.J., Cowan, D.A., 2003. Review and re-analysis of domain-specific 16 S primers. J. Microbiol. Methods 55, 541-555.

Bell, K.S., Philp, J.C., Aw, D.W., Christofi, N., 1998. The genus Rhodococcus. J. Appl. Microbiol. 85, 195-210.

Calheiros, C.S.C., Rangel, A.O.S.S., Castro, P.M.L., 2009. Treatment of industrial wastewater with two-stage constructed wetlands planted with Typha latifolia and Phragmites australis. Bioresour. Technol. 100, 3205-3213.

Carballa, M., Omil, F., Lema, J.M., Llompart, M., García-Jares, C., Rodríguez, I., Gómez, M., Ternes, T., 2004. Behavior of pharmaceuticals, cosmetics and hormones in a sewage treatment plant. Water Res. 38, 2918-2926.

Caselles-Osorio, A., Garcia, J., 2007. Effect of physico-chemical pretreatment on the removal efficiency of horizontal subsurface-flow constructed wetlands. Environ. Pollut. 146, 55-63.

Daughton, C.G., Ternes, T.A., 1999. Pharmaceuticals and personal care products in the environment: agents of subtle change? Environ. Health Perspect. 107, 907-938.

Dowd, S.E., Callaway, T.R., Wolcott, R.D., Sun, Y., McKeehan, T., Hagevoort, R.G., Edrington, T.S., 2008. Evaluation of the bacterial diversity in the feces of cattle using 16S rDNA bacterial tag-encoded FLX amplicon pyrosequencing (bTEFAP). BMC Microbiol. 8.

Ellis, J.B., 2006. Pharmaceutical and personal care products (PPCPs) in urban receiving waters. Environ. Pollut. 144, 184-189.

Fent, K., Weston, A.A., Caminada, D., 2006. Erratum to "Ecotoxicology of human pharmaceuticals" [Aquatic Toxicology 76 (2006) 122-159] (DOI:10.1016/j.aquatox.2005.09.009). Aquat. Toxicol. 78, 207.

Garrido, L., Sánchez, O., Ferrera, I., Tomàs, N., Mas, J., 2014. Dynamics of microbial diversity profiles in waters of different qualities. Approximation to an ecological quality indicator. Sci. Total Environ. 468-469, 1154-1161.

Healy, M.G., Rodgers, M., Mulqueen, J., 2007. Treatment of dairy wastewater using constructed wetlands and intermittent sand filters. Bioresour. Technol. 98, 2268-2281.

Hijosa-Valsero, M., Matamoros, V., Martín-Villacorta, J., Bécares, E., Bayona, J.M. 2010. Assessment of full-scale natural systems for the removal of PPCPs from wastewater in small communities. Water Res. 44, 1429-1439.

Ibekwe, A.M., Lyon, S.R., Leddy, M., Jacobson-Meyers, M., 2007. Impact of plant density and microbial composition on water quality from a free water surface constructed wetland. J. Appl. Microbiol. 102, 921-936.

Johnsen, A.R., Winding, A., Karlson, U., Roslev, P., 2002. Linking of microorganisms to phenanthrene metabolism in soil by analysis of 13C-labeled cell lipids. Appl. Environ. Microbiol. 68, 6106-6113.

Joss, A., Zabczynski, S., Göbel, A., Hoffmann, B., Löffler, D., McArdell, C.S., Ternes, T.A., Thomsen, A., Siegrist, H., 2006. Biological degradation of pharmaceuticals in municipal wastewater treatment: proposing a classification scheme. Water Res. 40, 1686-1696.

Lawrence, J.R., Swerhone, G.D.W., Topp, E., Korber, D.R., Neu, T.R., Wassenaar, L.I., 2007. Structural and functional responses of river biofilm communities to the nonsteroidal anti-inflammatory diclofenac. Environ. Toxicol. Chem. 26, 573-582.

Li, J., Wen, Y., Zhou, Q., Xingjie, Z., Li, X., Yang, S., Lin, T., 2008. Influence of vegetation and substrate on the removal and transformation of dissolved organic matter in horizontal subsurface-flow constructed wetlands. Bioresour. Technol. $99,4990-4996$. 
Ligi, T., Oopkaup, K., Truu, M., Preem, J.K., Nõlvak, H., Mitsch, W.J., Mander, Ü., Truu, J., 2014. Characterization of bacterial communities in soil and sediment of a created riverine wetland complex using high-throughput 16S rRNA amplicon sequencing. Ecol. Eng. 72, 56-66.

Ma, J., Wang, Z., Yang, Y., Mei, X., Wu, Z., 2013. Correlating microbial community structure and composition with aeration intensity in submerged membrane bioreactors by 454 high-throughput pyrosequencing. Water Res. 47, 859-869.

McLellan, S.L., Huse, S.M., Mueller-Spitz, S.R., Andreishcheva, E.N., Sogin, M.L., 2010. Diversity and population structure of sewage-derived microorganisms in wastewater treatment plant influent. Environ. Microbiol. 12, 378-392.

Peralta, R.M., Ahn, C., Gillevet, P.M., 2013. Characterization of soil bacterial community structure and physicochemical properties in created and natural wetlands. Sci. Total Environ. 443, 725-732.

Quast, C., Pruesse, E., Yilmaz, P., Gerken, J., Schweer, T., Yarza, P., Peplies, J., Glöckner, F.O., 2013. The SILVA ribosomal RNA gene database project: improved data processing and web-based tools. Nucleic Acids Res. 41, D590-D596.

Quintana, J.B., Weiss, S., Reemtsma, T., 2005. Pathways and metabolites of microbial degradation of selected acidic pharmaceutical and their occurrence in municipal wastewater treated by a membrane bioreactor. Water Res. 39, 2654-2664.

Radjenović, J., Petrović, M., Barceló, D., 2009. Fate and distribution of pharmaceuticals in wastewater and sewage sludge of the conventional activated sludge (CAS) and advanced membrane bioreactor (MBR) treatment. Water Res. 43, 831-841.

Roesch, L.F.W., Fulthorpe, R.R., Riva, A., Casella, G., Hadwin, A.K.M., Kent, A.D., Daroub, S.H., Camargo, F.A.O., Farmerie, W.G., Triplett, E.W., 2007. Pyrosequencing enumerates and contrasts soil microbial diversity. ISME J. 1, 283-290.

Roh, S.W., Abell, G.C.J., Kim, K.H., Nam, Y.D., Bae, J.W., 2010. Comparing microarrays and next-generation sequencing technologies for microbial ecology research. Trends Biotechnol. 28, 291-299.

Ruiz, C., Blanco, A., Pastor, F.I.J., Diaz, P., 2002. Analysis of Bacillus megaterium lipolytic system and cloning of LipA, a novel subfamily I.4 bacterial lipase. FEMS Microbiol. Lett. 217, 263-267.

Schloss, P.D., Westcott, S.L., Ryabin, T., Hall, J.R., Hartmann, M., Hollister, E.B., Lesniewski, R.A., Oakley, B.B., Parks, D.H., Robinson, C.J., Sahl, J.W., Stres, B., Thallinger, G.G., Van Horn, D.J., Weber, C.F., 2009. Introducing mothur: open-source, platform-independent, community-supported software for describing and comparing microbial communities. Appl. Environ. Microbiol. 75, 7537-7541.

Seong, J.P., Jerng, C.Y., Shin, K.S., Eung, H.K., Yim, S., Cho, Y.J., Gi, M.S., Lee, D.G., Seung, B.K., Lee, D.U., Woo, S.H., Koopman, B., 2007. Dominance of endosporeforming bacteria on a rotating activated bacillus contactor biofilm for advanced wastewater treatment. J. Microbiol. 45, 113-121.
Sleytr, K., Tietz, A., Langergraber, G., Haberl, R., Sessitsch, A., 2009. Diversity of abundant bacteria in subsurface vertical flow constructed wetlands. Ecol. Eng. 35 1021-1025.

Stottmeister, U., Wießner, A., Kuschk, P., Kappelmeyer, U., Kästner, M., Bederski, O., Müller, R.A., Moormann, H., 2003. Effects of plants and microorganisms in constructed wetlands for wastewater treatment. Biotechnol. Adv. 22 93-117.

Teixeira, L.C.R.S., Peixoto, R.S., Cury, J.C., Sul, W.J., Pellizari, V.H., Tiedje, J., Rosado A.S., 2010. Bacterial diversity in rhizosphere soil from Antarctic vascular plants of Admiralty Bay, maritime Antarctica. ISME J. 4, 989-1001.

Ternes, T.A., Bonerz, M., Herrmann, N., Teiser, B., Andersen, H.R., 2007. Irrigation of treated wastewater in Braunschweig, Germany: an option to remove pharmaceuticals and musk fragrances. Chemosphere 66, 894-904.

Tietz, A., Hornek, R., Langergraber, G., Kreuzinger, N., Haberi, R., 2007. Diversity of ammonia oxidising bacteria in a vertical flow constructed wetland. Water Sci. Technol., 241-247.

Truu, M., Juhanson, J., Truu, J., 2009. Microbial biomass, activity and community composition in constructed wetlands. Sci. Total Environ. 407, 3958-3971.

Verlicchi, P., Zambello, E., 2014. How efficient are constructed wetlands in removing pharmaceuticals from untreated and treated urban wastewaters? A review. Sci. Total Environ. 470-471, 1281-1306.

Wang, Y., Sheng, H.F., He, Y., Wu, J.Y., Jiang, Y.X., Tam, N.F.Y., Zhou, H.W., 2012. Comparison of the levels of bacterial diversity in freshwater, intertidal wetland, and marine sediments by using millions of illumina tags. Appl. Environ. Microbiol. $78,8264-8271$

Winker, M., Clemens, J., Reich, M., Gulyas, H., Otterpohl, R., 2010. Ryegrass uptake of carbamazepine and ibuprofen applied by urine fertilization. Sci. Total Environ. 408, 1902-1908.

Zhang, D., Gersberg, R.M., Ng, W.J., Tan, S.K., 2014. Removal of pharmaceuticals and personal care products in aquatic plant-based systems: a review. Environ. Pollut. 184, 620-639.

Zhang, D.C., Mörtelmaier, C., Margesin, R., 2012a. Characterization of the bacterial archaeal diversity in hydrocarbon-contaminated soil. Sci. Total Environ. 421-422, 184-196.

Zhang, D.Q., Gersberg, R.M., Zhu, J., Hua, T., Jinadasa, K.B.S.N., Tan, S.K., 2012b. Batch versus continuous feeding strategies for pharmaceutical removal by subsurface flow constructed wetland. Environ. Pollut. 167, 124-131.

Zhang, T., Shao, M.F., Ye, L., 2012c. 454 Pyrosequencing reveals bacterial diversity of activated sludge from 14 sewage treatment plants. ISME J. 6 1137-1147. 